\title{
CANCER AS A SEQUEL TO WAR WOUNDS
}

\author{
LfoN Gillis and Stanley Lfe, LoNidon, ENGlayd
}

From Queen .Mary's Hospital, Rochampton, and Westminster Hospital, London

The purpose of this paper is to draw attention to a late complication of war wounds which, though rare, is important and deserves recognition. Twenty-four cases are presented in which a squamous carcinoma has arisen at the site of the wound; they have been selected from a considerably larger number because they allow no reasonable doubt as to the relationship of the carcinoma to the wound. Four of the cases are described in greater detail in order to illustrate certain special points afterwards discussed.

Chronically irritated tissues have long been recognised as fertile soil for the development of squamous carcinoma. In 1835 Caesar Hawkins of St George's Hospital, London, writing of "warty tumours in cicatrices," noted their occurrence in scars of burns and of flogging, and, in one instance, in an old gunshot wound of the leg. Carcinoma has been reported as a late complication of thermal, chemical and X-ray burns, of healed lupus, of chronic varicose ulcers (Marjolin's ulcer), of chronic tuberculous and osteomyelitic sinuses and of anal fistulae. Among pensioners of the first world war we have found other instances complicating sacral bed-sores, trophic ulcers and callosities on anaesthetic feet, and the scars of frostbite and flash burns. These cases have been excluded from the present series, as have some examples of sarcoma that appear to have arisen in deeper tissues around scars or foreign bodies. Some of them, however, are appended for interest in Table II.

Clinical material-.The clinical features of the twenty-four cases of the present series are set out in Table I, and selected cases are illustrated in Figures 1 to 14. It will be realised that the cases form a highly selected group: all are males, and all were of military age during the first world war. The reasons for the preponderance of lower limb wounds are discussed below.

\section{TYPICAL CASE REPORTS}

Case 5-At the age of twenty-four years the patient received a wound in the upper part of the right thigh with fracture of the femur and consequent osteomyelitis. The sinuses never healed and the scars were extensive and adherent to bone. In 1943 increasing fetor of the discharge was noted and radiography showed extensive disease of the femoral shaft. Granulations around a sinus that had discharged continuously for twenty-five years were examined and showed clear evidence of carcinoma. The surgeon in charge recorded his conviction that the growth would be of low malignancy, and aimed to preserve an adequate stump by a guillotine amputation leaving five inches of femur. The operation was followed by early local recurrence and enlargement of the inguinal glands; and the patient died within a year. The histological picture showed that the tumour was of high malignancy.

Comment-In this case it seems that the surgeon shared the common misconception that it is unnecessary to take very seriously carcinoma arising in scar tissue. This view finds considerable support in the literature; thus Harrison, writing as recently as 1938, stated: "We have not found in the literature any instances of a carcinoma secondary to osteomyelitis in which there were distant metastases. Biopsy of nearby enlarged nodes has shown only chronic lymphadenitis." Bereston and Ney (1941), however, collected from the literature seven cases with proved metastases and added two of their own. It is the experience of the present writers, as will be seen from several of the cases presented, that the tumours may become very malignant, developing rapidly, infiltrating extensively, and disseminating widely. They must be treated as urgently and radically as any other carcinoma.

Case 7-Patient wounded in the right leg in 1918 at the age of eighteen years. The tibia was extensively damaged, and in thirty years the resultant sinuses never healed completely. There

vOL. 33 B, No. 2 , MAY 1951

167 


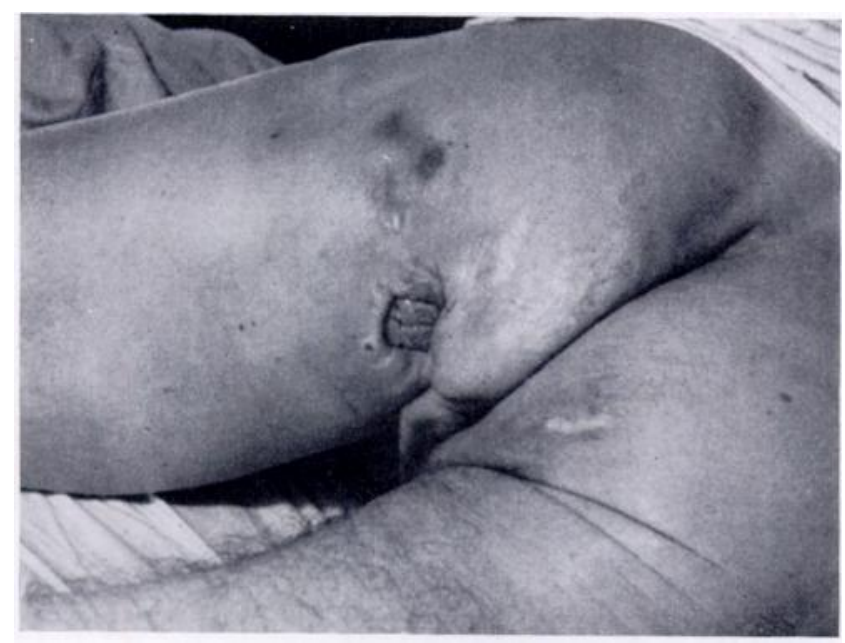

FIG. 1

Case 6-Sinus cancer. Chronic sinus of the left buttock with development of carcinoma twenty-nine years after gunshot wounds.

FIG. 2

Case 6-Low power section showing histological appearance. Squamouscell carcinoma.
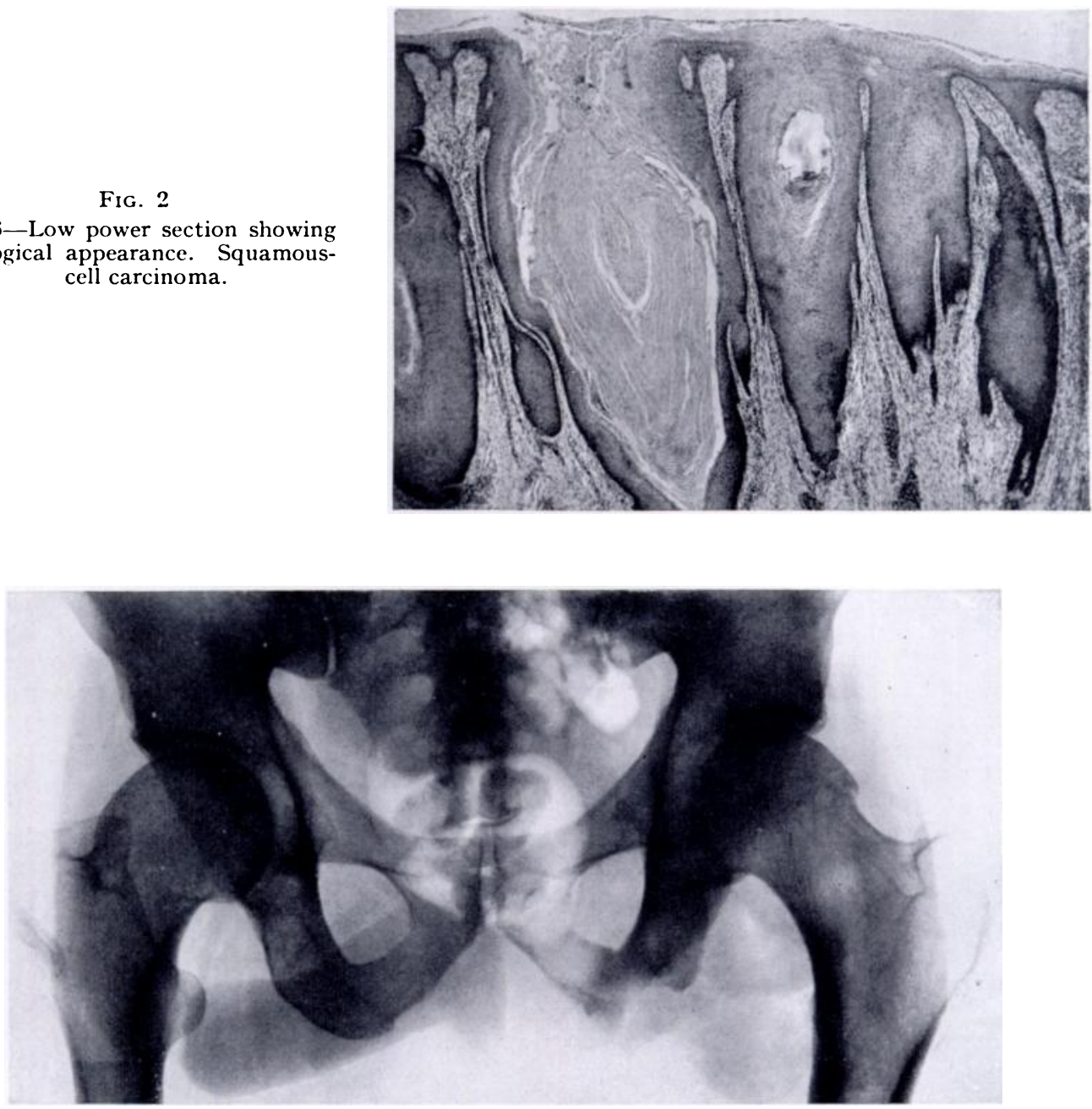

Fig. 3

Case 6-Radiograph showing erosion of the left ischio-pubic ramus. 


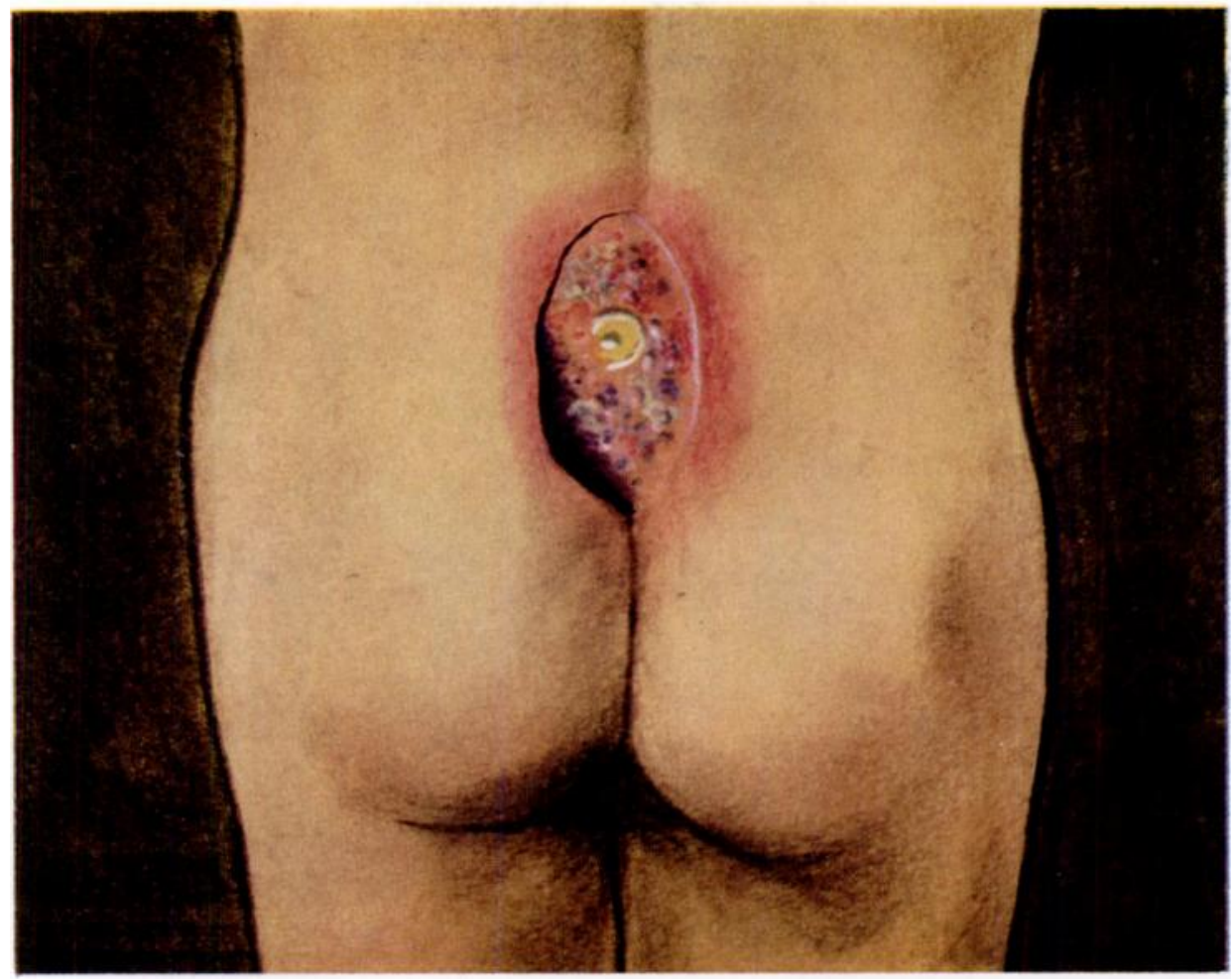

Fici. 9

Case 10-Sinus cancer. Deep ulcer in the sacral area after arrest of a carcinoma which developed thirty years after gunshot wounds. (13y courtesy of sir Stanford Cade.)

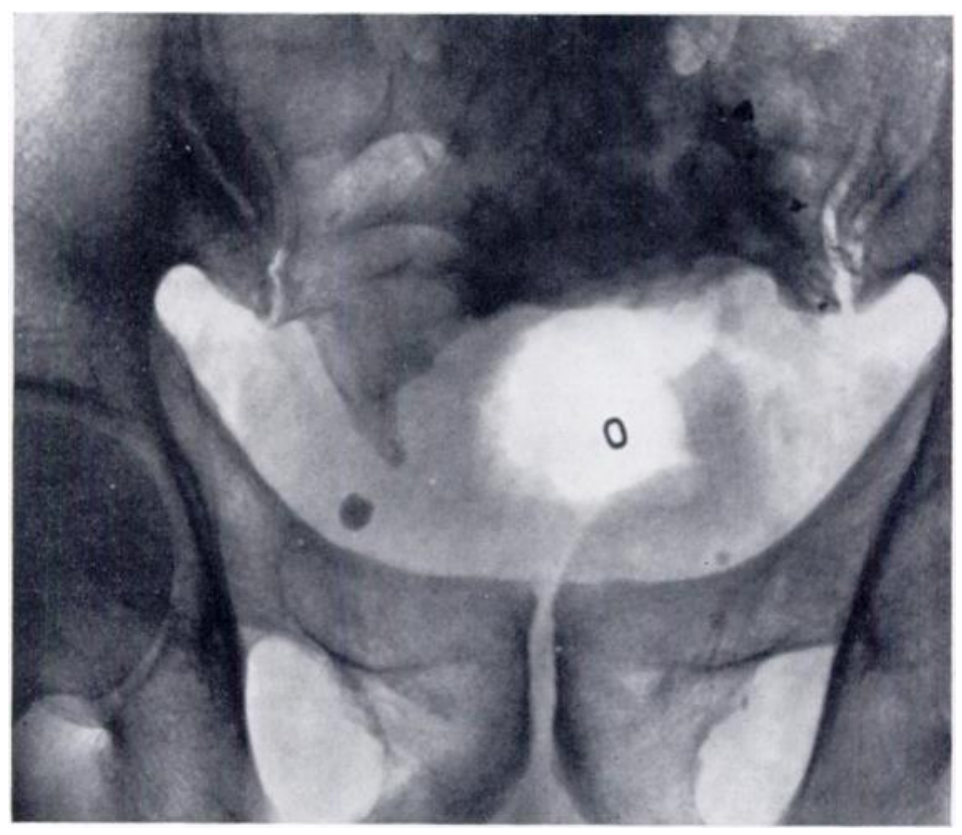

FIG. 10

Case 10-Radiograph shows extensive erosion of the sacrum. 


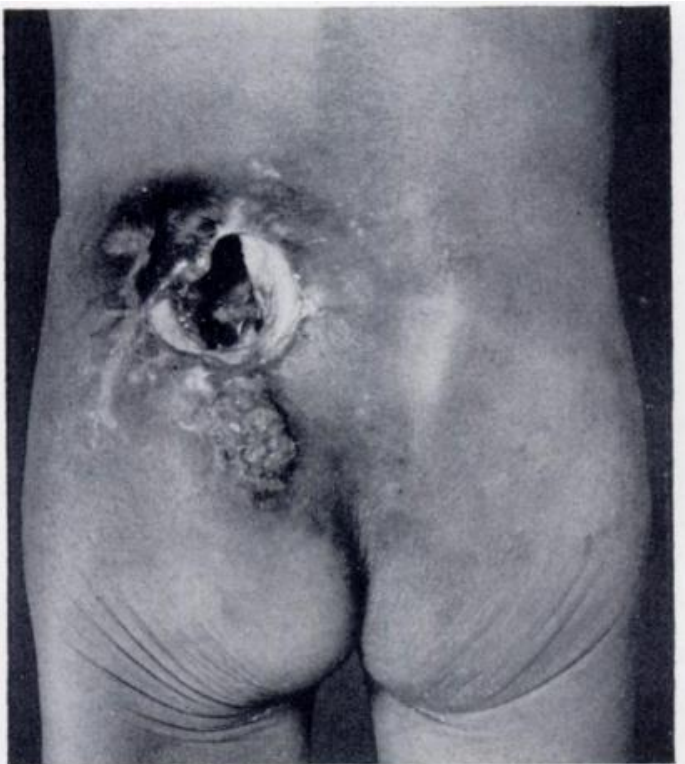

Fig. 4

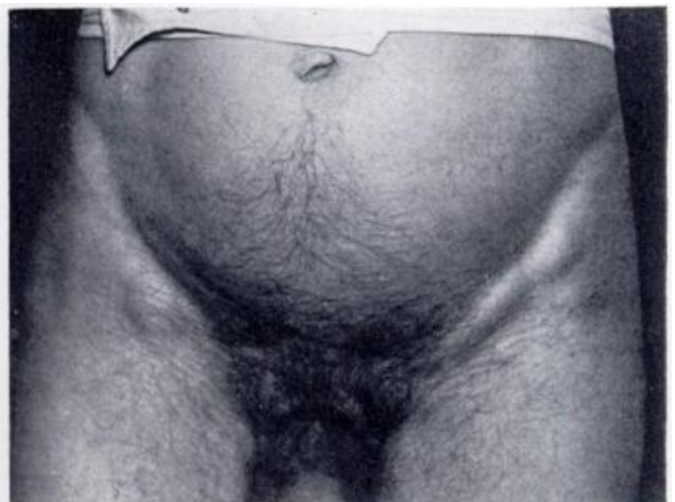

FIG. 5

Case 8 - Sinus cancer. Figure 4 shows a deep chronic ulcer crater with development of carcinoma thirty-three years after gunshot wounds. Figure 5malignant enlargement of the inguinal glands.

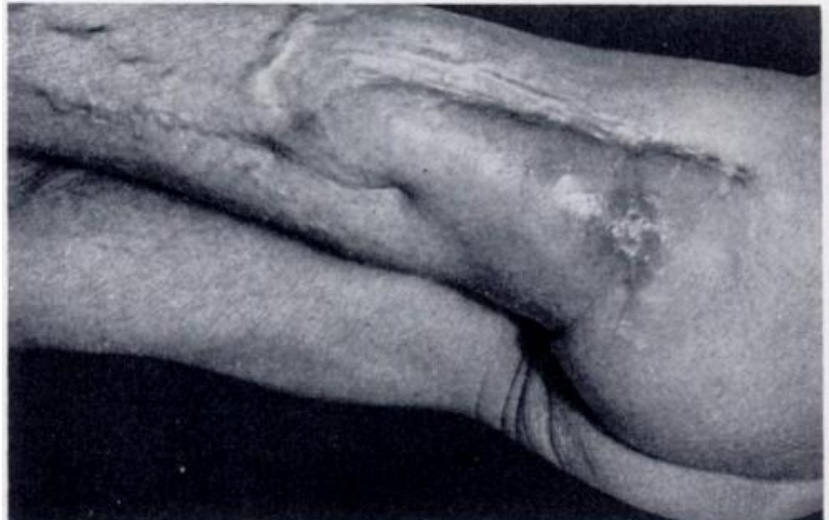

Fig. 6

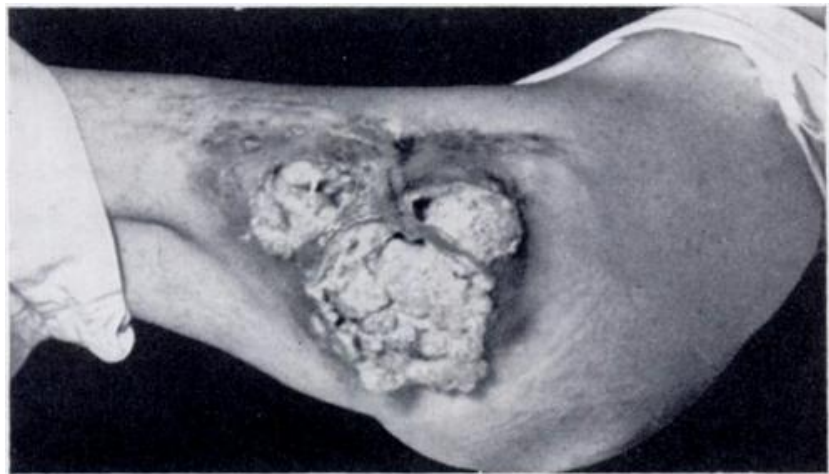

Fig. 7

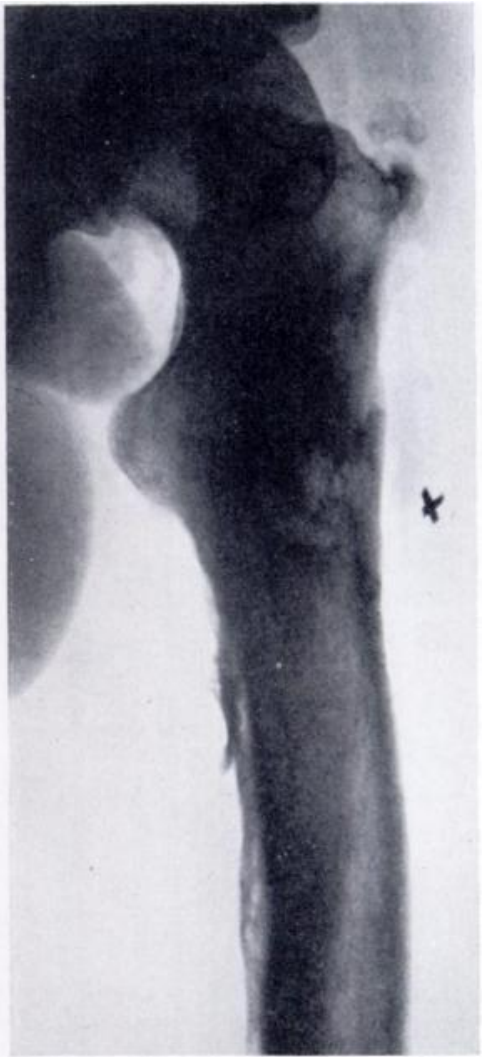

FIG. 8

Case 9-Sinus cancer. Figure 6-Commencement of carcinoma in a discharging sinus twenty-nine years after gunshot wounds. The rapidity of growth can be judged from comparison with Figure 7 , a photograph taken only ten weeks later. Radiograph (Fig. 8) shows osteitis of the upper end of the femur.

vol. $33 \mathrm{~B}$, NO. 2, MAY 1951

B2 


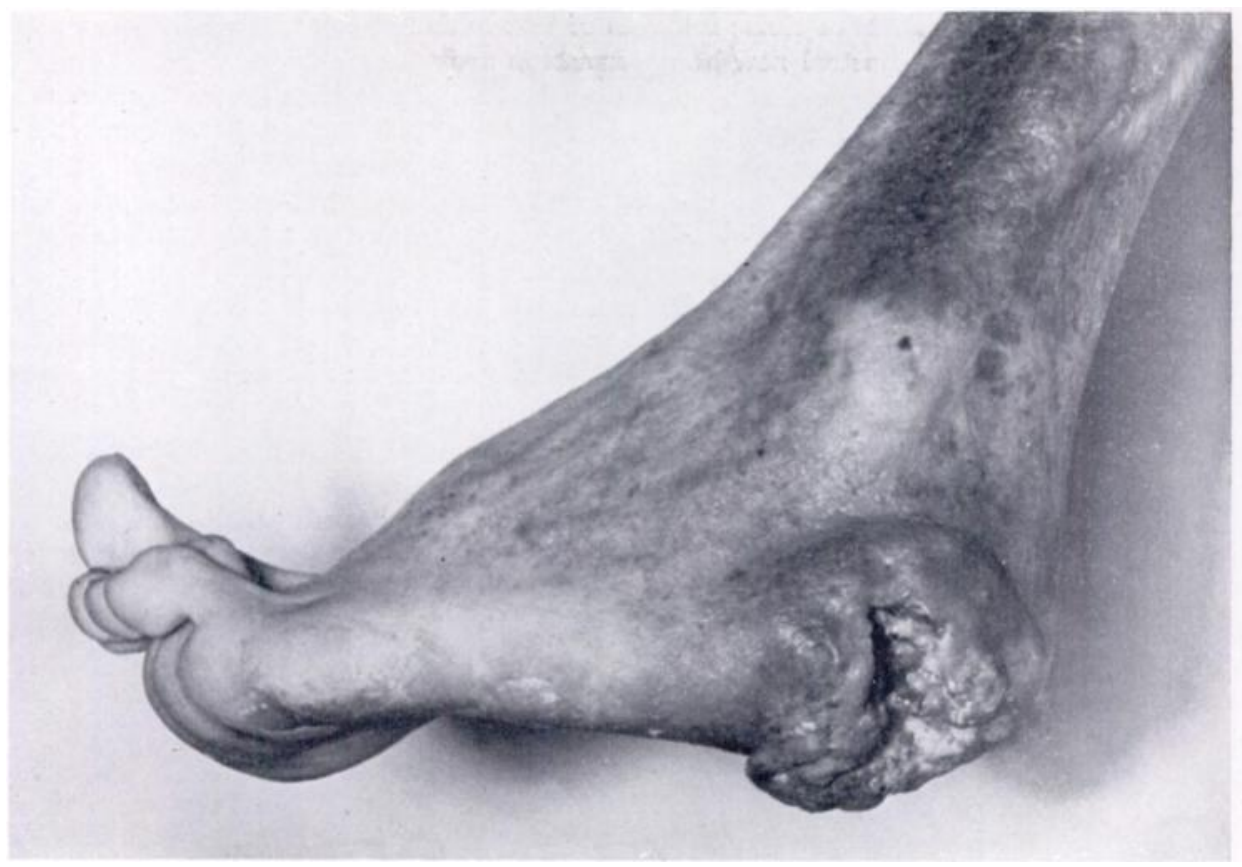

Fici. 11

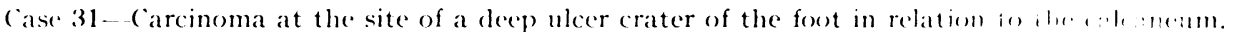

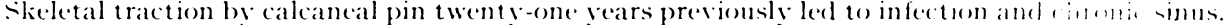
(sipecimen in the museum of the Royal college of Surgerons.)

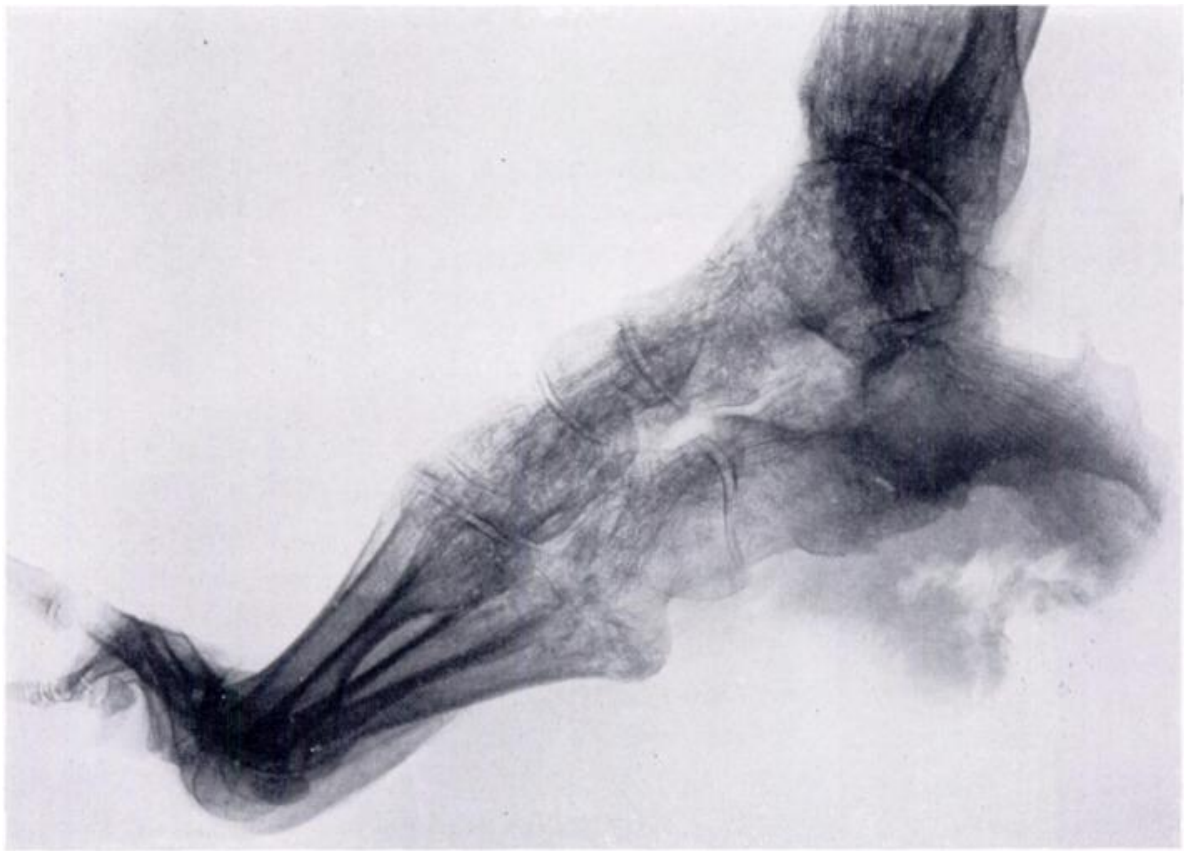

Fis. 12

Case 31-Radiograph shows extensive erosion of calcaneum. Yote the soft-tissue swelling.

VOL. 33 B, No. 2, MAY 1951 
were many sequestra and he had at least seven operations. In 1946 radiographs showed large cavities in upper and lower ends of tibia; sclerosis of surrounding bone and synostosis with fibula opposite each cavity; and periosteal new bone formation around middle third of fibula. At that time there was much discharge, and histological examination of curettings from the sinus showed squamous-cell carcinoma. Amputation was performed eleven inches below the greater trochanter. A year later he was readmitted with an enlarged inguinal gland, clinically inoperable. His general condition was poor and radiographs of the chest showed a collapsed right lower lobe with effusion. He died within three weeks of admission. Autopsy revealed carcinoma in the amputation stump and in the inguinal glands, as well as in the lungs, diaphragm and pleura.

Comment-This case presents certain notable features: the malignant change began within a sinus and was already well established before much surface change was evident; an increase in the amount and fetor of the discharge first called attention to the neoplasm; the tumour itself was very malignant and metastasized widely.

Case 9-Patient aged thirty-six years at the time of wounding in the left thigh by bomb fragments in 1918. Apparently no gross bone injury. He was in various hospitals for four years and underwent a number of operations for osteomyelitis of the femur. Sinuses persisted in spite of treatment and never healed completely. In 1945 the presence of a sequestrum was noted but it was not removed. In 1947 a biopsy specimen taken from suspicious looking tissue at the margin of a sinus showed squamous-cell carcinoma. The rapid progress of the disease can be seen from the photographs (Figs. 6 and 7). No curative treatment was attempted and the patient died early in 1948. Autopsy showed extensive osteomyelitis of the femur with a massive carcinoma, but no visceral metastases. Amyloid changes were found in liver and spleen.

Case 22-In 1918, when twenty-eight years of age, the patient received a bullet wound of the right side of the face. The horizontal ramus of the mandible was shattered and there was much loss of soft tissue. The reconstructive programme occupied three years, after which the wound was healed, and there was fibrous union of the mandible, though movement was limited by scar tissue (Figs. 13 and 14). He remained well until 1942 when a malignant ulcer appeared on the mucosal aspect of the cheek close to a skin inlay. He was treated with high-voltage X-rays but, although the growth was arrested, an ulcer persisted; and in 1950 the disease again became active. Radical resection with repair by pedicle flaps was undertaken and the patient is alive, though probably with disease.

Comment-This case differs from the preceding three in that bone infection had not persisted and there were no sinuses. The carcinoma presumably arose in unstable scar tissue, thus resembling those occurring in old burns or lupus scars. Comparable cases are numbers 27, 28 and 30 in Table II.

\section{PRE-GANGEROUS CHANGES}

In a few cases the wound has been seen in a state of hyperkeratosis that could be regarded as pre-cancerous. Clinical details of three such cases are given in Table III, and one case is illustrated in Figures 15 and 16. It may be claimed that in these cases treatment has prevented the onset of malignancy.

\section{DISCUSSION}

Sinus cancer-This term is chosen to designate the larger of the two groups into which our series may be subdivided, comprising sixteen cases. There is a history of an osteomyelitic sinus discharging for long periods, often throughout the latent interval. The tumour sometimes arises deep in the sinus and may reach a considerable size before becoming manifest on the surface. Obviously these cases are analogous to carcinomata arising in other types of sinuses and fistulae, and well recognised as a complication of chronic osteomyelitis of civilian origin (Hueper 1942, Niebauer 1946). They occur almost always in the lower limb, buttocks or sacral area; we ourselves have never seen an undoubted example in the upper limb, though a few have been recorded, one of them by Volkmann (quoted by Bereston and Ney 1941). This heavy preponderance of lower limb involvement is not merely a reflection of the distribution of war wounds in general nor of the bones affected by osteomyelitis. In 1929 an analysis of limb wounds still disabling enough to require pensions (Sandison 1929) showed them to be distributed almost equally between arm and leg; while osteomyelitis, in a series of 2,400 cases admitted to the Massachusetts General Hospital and recorded by Benedict 


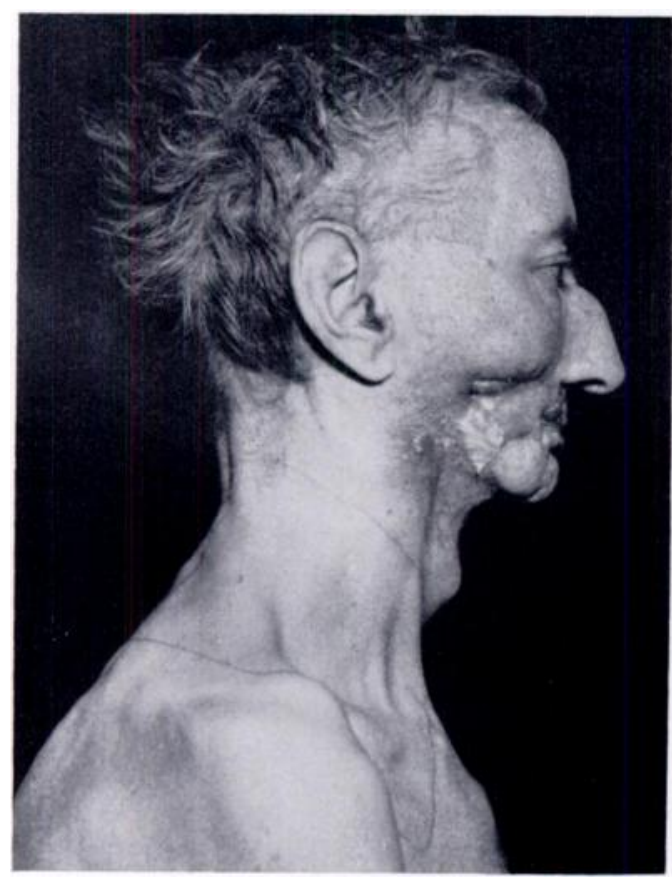

FIG. 13

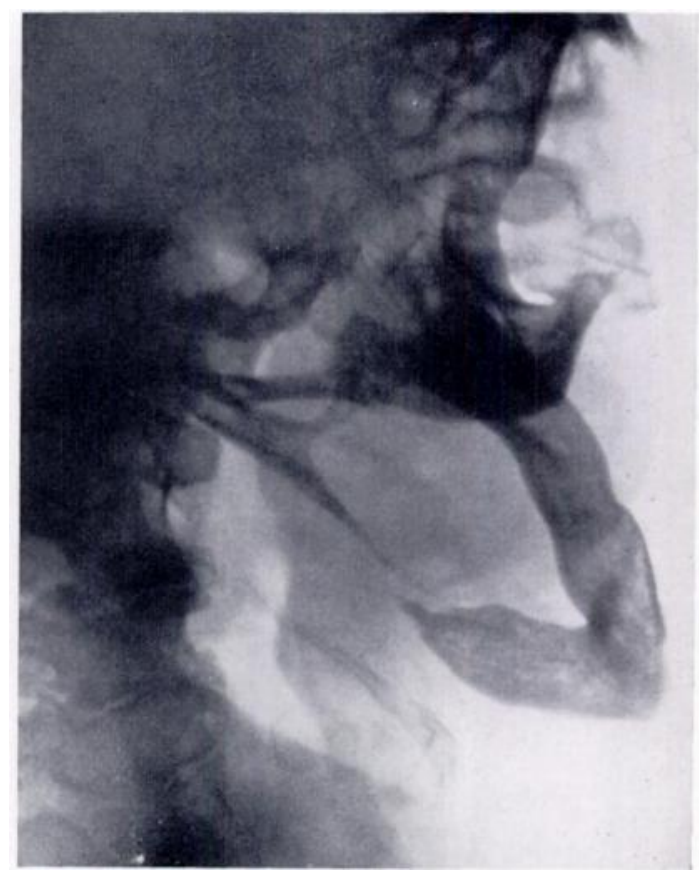

FIG. 14

Case 22--Scar cancer. Figure 13-Treated carcinoma at the site of an old gunshot wound of the mandible sustained twent $y$-four vears previously. The wounds had remained healed for twenty-one years after plastic reconstruction. Figure 14-Radiographic appearance; large defect in the right mandibular ramus.

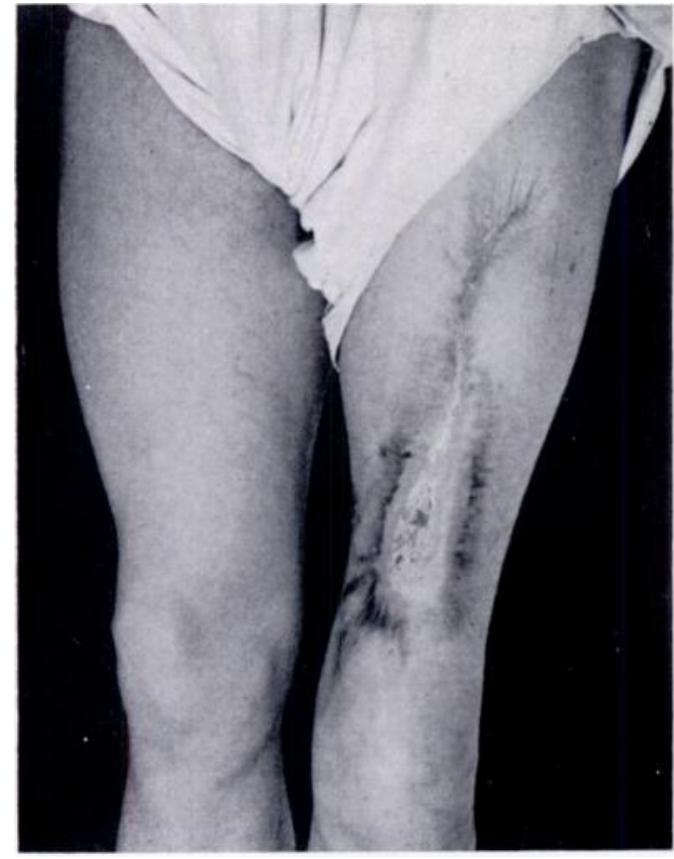

FIG. 15

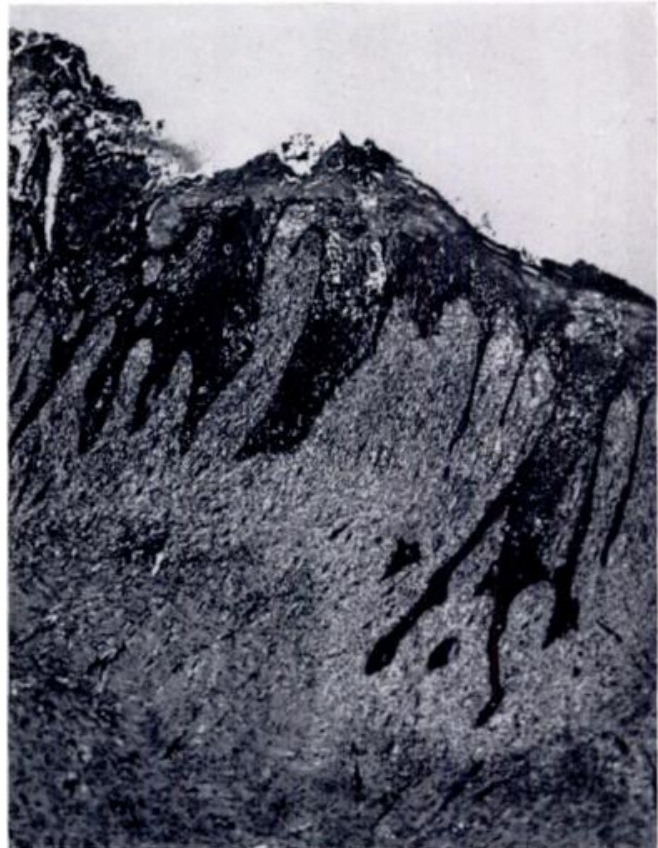

FIG. 16

Case 32-Pre-cancerous changes in scar. Figure 15-Photograph showing adherent scar with pre-cancerous changes thirty years after gunshot wounds. Figure 16- Histological section shows marked proliferative activity of the epithelium.

vol. $33 \mathrm{~B}$, No. 2, MAY 1951 


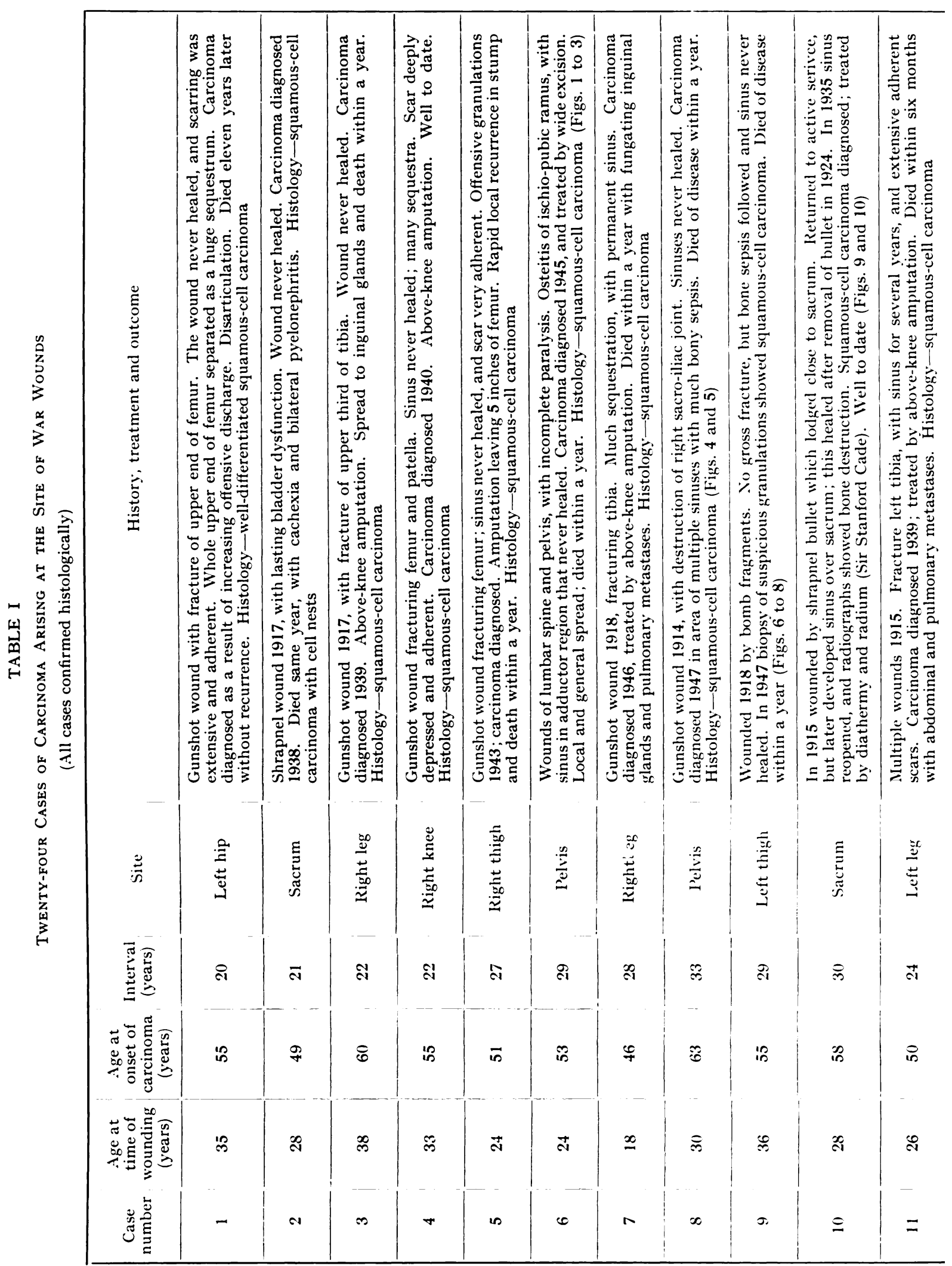

THE JOURNAL OF BONE AND JOINT SURGERY 


\begin{tabular}{|c|c|c|c|c|c|c|c|c|c|c|c|c|}
\hline 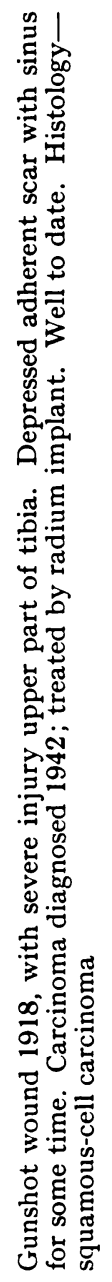 & 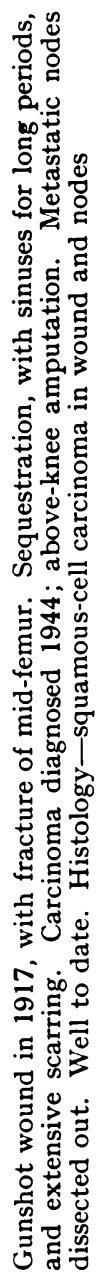 & 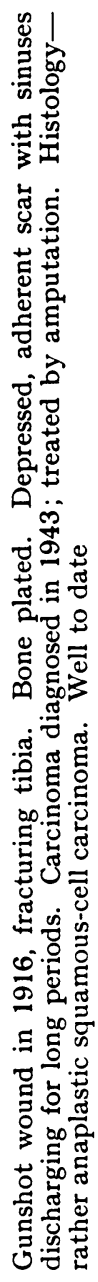 & 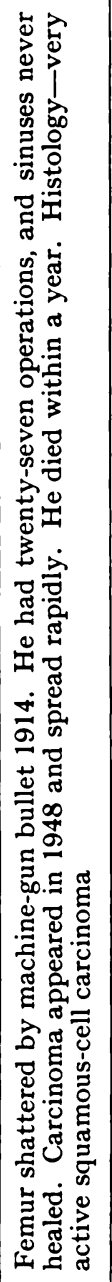 & 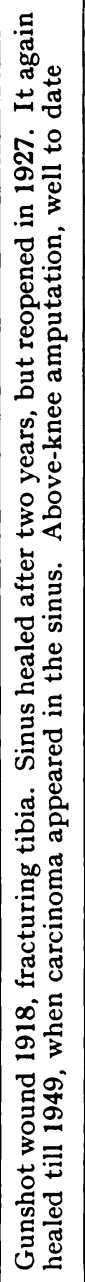 & 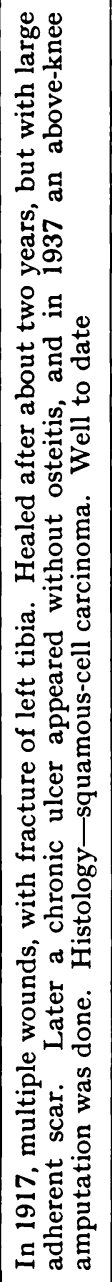 & 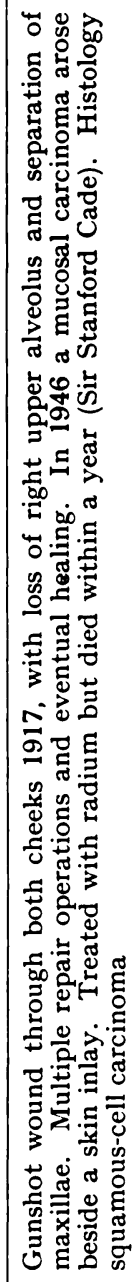 & 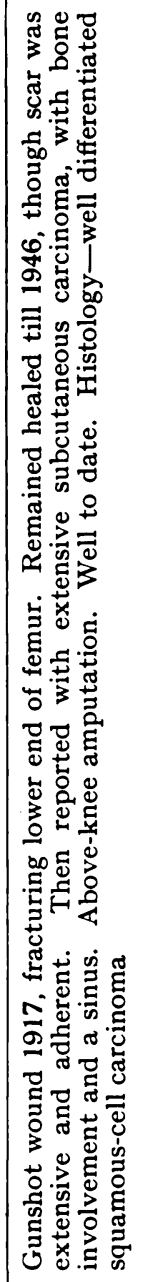 & 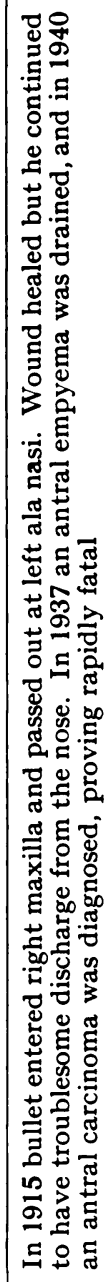 & 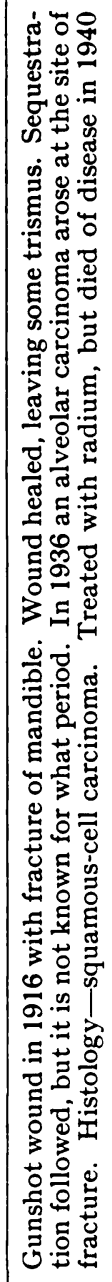 & 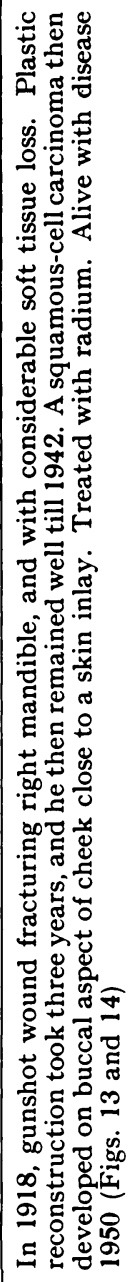 & 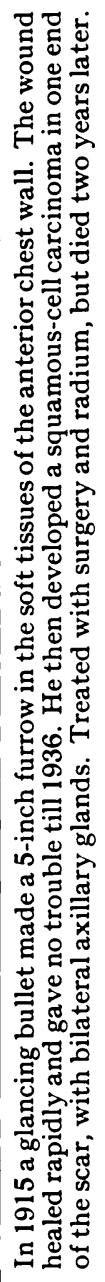 & 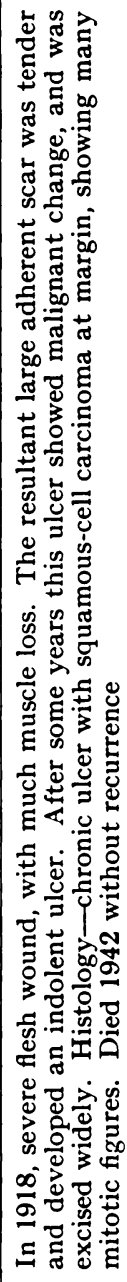 \\
\hline 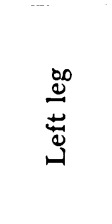 & 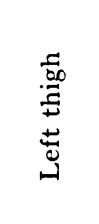 & 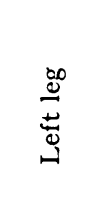 & 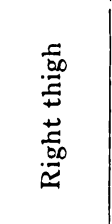 & 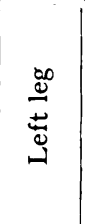 & 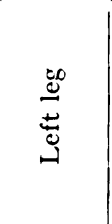 & 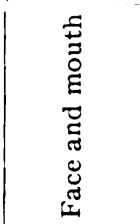 & 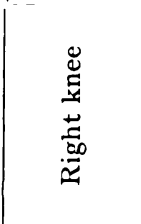 & $\underset{\mathscr{\varpi}}{\mathscr{\Psi}}$ & 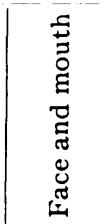 & 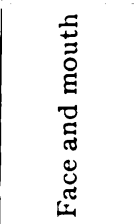 & $\bar{u}$ & 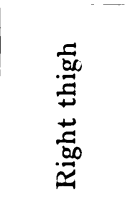 \\
\hline $\mathbb{\pi}$ & $\hat{\mathrm{N}}$ & $\hat{N}$ & $\stackrel{\infty}{\sim}$ & $\overline{\text { m }}$ & $\bar{N}$ & $\stackrel{乛}{2}$ & ని & $\vec{N}$ & సి & $\vec{N}$ & $\bar{a}$ & $\stackrel{\infty}{\sim}$ \\
\hline f & $\overline{0}$ & ช్ర & ชิ & in & 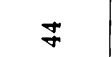 & in & $\mathscr{q}$ & f & in & is & is & 18 \\
\hline N & $\vec{m}$ & $\mathscr{m}$ & "ా & $\stackrel{\infty}{N}$ & $\approx$ & జ & สิ & N & $\mathscr{m}$ & $\stackrel{\text { ని }}{ }$ & ले & 5 \\
\hline$\cong$ & 9 & $\Xi$ & in & $\stackrel{0}{0}$ & $=$ & $\stackrel{\infty}{\sim}$ & $\stackrel{2}{2}$ & สิ & $\bar{N}$ & สี & ఇָ & $\mathbb{N}$ \\
\hline
\end{tabular}




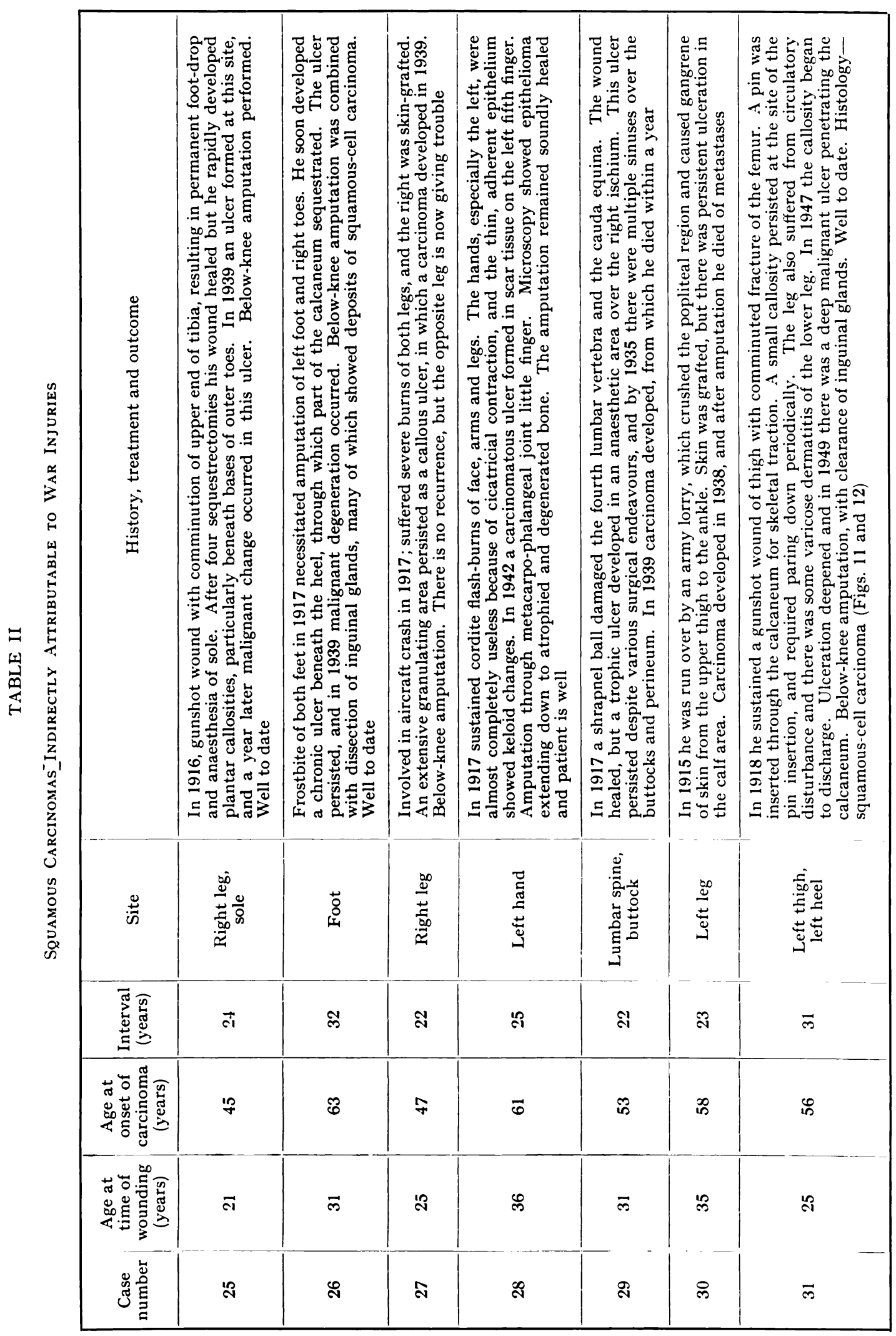

THE JOURNAL OF BONE AND JOINT SURGERY 


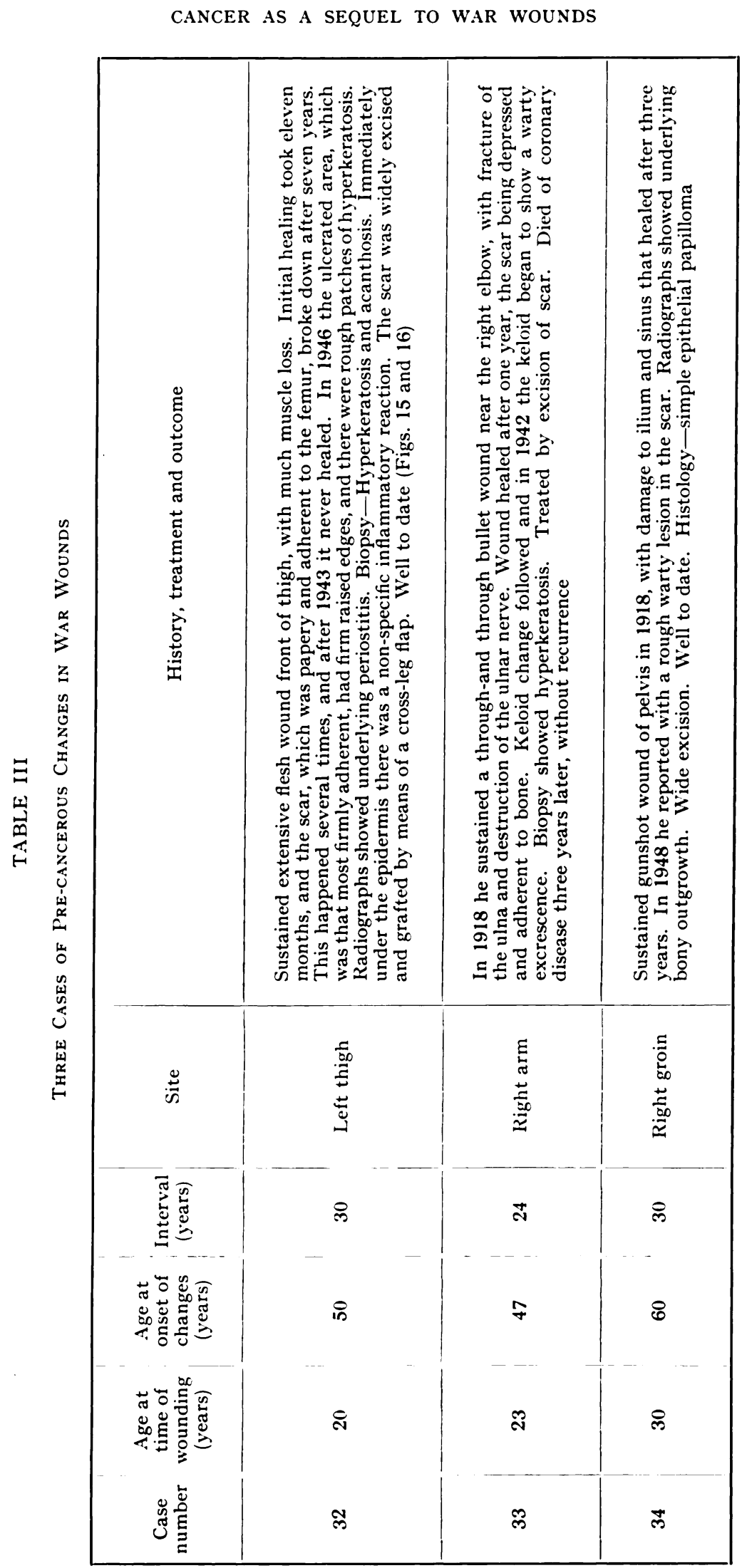

vol. 33 B, No. 2, MAY 1951 
(1931), involved lower and upper limbs in the ratio of about three or four to one (Table IV). But it is in the lower limb that massive wounds with severe bone damage are treated conservatively and give rise to the persistent sinuses liable to undergo malignant change; it is common experience that such conditions are very rare in other regions of the body.

TABLE IV

Anatomical Distribution of War Wounds, Osteomyelitis and Sinus Carcinoma

\begin{tabular}{|c|c|c|c|c|}
\hline Site & $\begin{array}{c}\text { Pensioned } \\
\text { war wounds } \\
\text { (Sandison 1929) }\end{array}$ & $\begin{array}{c}\text { Osteomyelitis } \\
\text { (Benedict 1931) }\end{array}$ & $\begin{array}{c}\text { Sinus carcinoma } \\
\text { (Benedict 1931) }\end{array}$ & Present series \\
\hline Upper limb & 113,000 & 415 & None & None \\
\hline Lower limb & 117,000 & 1,358 & $\begin{array}{c}16, \text { including those } \\
\text { in pelvic area }\end{array}$ \\
\hline
\end{tabular}

Scar cancer-There were at least seven of these in our series. There may be no history of prolonged infection, and no symptoms during the latent interval. The lower limb is not predominantly affected (this is also true of a series of burn scar cancers published by Treves and Pack in 1930). The growth starts in an area of thin, poorly nourished and brittle epithelium based on more or less extensive fibrous tissue and often firmly adherent to bone. In several of our cases the lesion was in the mouth, twice clearly in relation to skin inlays. The group corresponds in all respects to tumours occurring in other scars, such as those of burns, lupus and radiation. It is important to realise that even in this group, with little or no actual ulceration during the latent period, long continued carcinogenic influences are at work. Carcinoma does not occur in sound, supple, "resting" scars such as those produced by abdominal surgery. The dangerous scar is one in which cell division has been continuously stimulated for years under worsening conditions of deficient circulation and mechanical restriction. Such factors, it is easy to conceive, may lead to accumulation of metabolites, or to local deficiencies, eventually resulting in abnormal mitosis.

Incidence-Carcinomatous change as a complication of wounds and scars is clearly uncommon. McAnally and Dockerty (1949) found in the records of the Mayo Clinic nine cases of carcinoma in 4,000 cases of osteomyelitis, three in 3,000 cases of anal fistula, and one in 1,500 cases of empyema. Benedict (1931) in his 2,400 cases of osteomyelitis found twelve complicated by carcinoma. Such figures, however, tend to obscure the true position. What is necessary is to determine not the incidence of carcinoma in all sinuses or scars, but in those that are twenty years old or more; on this basis the incidence of malignant change will certainly reach a much higher figure. No estimate has been found in the literature, and unfortunately our system of records does not enable us to make an assessment. It is not possible, for instance, to determine the number of men whose sinuses persisted for long periods, or to discover the total number of carcinomata that have arisen.

Latent interval-In the present series no carcinoma developed sooner than eighteen years after the injury; and cases are still occurring more than thirty years after the end of the war. There is no method at our disposal for determining whether a peak has been reached; but it seems a likely supposition that, if there is in a given wound a tendency to malignant change, that tendency will increase as the years pass, right up to the patient's death. There is no apparent relation between the latent interval and the age of the patient. A long interval is well recognised in other post-traumatic carcinomata: twenty to fifty years in cases of osteomyelitic sinuses, ten years or more in X-ray dermatitis, ten to forty years in varicose ulceration, and so on. Burn scars, however, occasionally undergo early malignant change, and Treves and Pack (1930) distinguished a group of middle-aged patients with what they 
called "acute burn scar cancers," appearing within months or even weeks of the injury. They emphasized, however, that in patients of this age the possibility of some earlier, forgotten trauma to the affected area must be allowed. In such cases the burn is to be regarded as the precipitating, rather than the predisposing, cause.

\section{CONCLUSIONS}

A patient with a chronic discharging sinus or an extensive adherent scar is never safe from the risk of malignant change. Examples are still occurring more than thirty years after the end of the first world war. The possibility should be kept in mind by those concerned with the long-term treatment of wounds of this kind. Reasonable prophylactic measures would be: excision of adherent or unstable scars with, if necessary, their replacement by suitable pedicle flaps having a good blood supply; and earlier amputation if a osteomyelitic sinus persists for several years and does not yield to treatment. Supervision of doubtful cases should be frequent and should not be relaxed with the passage of the years. Warty changes or indolent ulceration of scars should be regarded with grave suspicion and investigated by biopsy. Any increase in pain or discharge in association with a sinus should receive prompt attention. Finally, if malignant change supervenes, treatment should be as speedy and as radical as with any other cancer. At least thirteen of our twenty-four patients have died of cancer.

We have pleasure in recording our thanks to the Director-General of Medical Services of the Ministry of Pensions, not only for permission to publish this clinical material, but for the invaluable help which he and his staff have given us; and to the Mledical Superintendent of Queen Mary's Hospital, Roehampton, and his staff; without their help it would have been impossible to gather the necessary data. We also wish to thank Sir Stanford Cade for his encouragement and advice, and for his ready permission for his own cases to be included; Dr Mackenzie Douglas, Pathologist at Queen Mary's Hospital, for bringing many of the cases to our notice and for providing much of the histological material; and Professor R. J. V. Pulvertaft, of Westminster. Medical School, for preparing the photomicrographs, and for criticism of the histological material.

\section{REFERENCES}

Benedict, E. B. (1931): Carcinoma in Osteomyelitis. Surgery, Gynecology and Obstetrics 53, 1.

Bereston, E. S., and Ney, C. (1941): Squamous-cell Carcinoma Arising in a Chronic Osteomyelitis Sinus Tract with Metastasis. (Quoting Volkmann's case.) Archives of Surgery, 43, 257.

Harrison, J. H. (1938): Epidermoid Carcinoma in Osteomyelitis. American Journal of Cancer, 32, 527.

Hawkins, Caesar (1835): Cases of Warty Tumours in Cicatrices. Medico-Chirurgical Transactions, $19,19$. Hueper, W. C. (1942): Occupational Tumors and Allied Diseases. Baltimore: Chas. C. Thomas, Chap. 2. An extensive bibliography is appended.

Marjolin (1828): Dictionnaire de Médecin.

McAnally, A. K., and Dockerty, M. B. (1949): Carcinoma Developing in Chronic Draining Cutaneous Sinuses and Fistulae. Surgery, Gynecology and Obstetrics, 88, 87. There is a good bibliography.

Niebauer, J. J. (1946): Development of Squamous-cell Carcinomata in the Sinus Tracts of Chronic Osteomyelitis. Journal of Bone and Joint Surgery, 28, 280.

Sandison, A. (1931): Casualties Dealt with by the Ministry of Pensions, in History of the Great War Based on Official Documents. Medical Services. Volume Casualties and Medical Statistics. London: H.M. Stationery Office.

Treves, N., and PACK, G. T. (1930): The Development of Cancer in Burn Scars: An Analysis and Report of Thirty-four Cases. Surgery, Gynecology and Obstetrics, 51, 749. 